\title{
Pharmaceutical significance of cellulose: A review
}

\author{
S. Kamel1,3*, N. Ali ${ }^{1}$, K. Jahangir 1 , S. M. Shah ${ }^{1}$, A. A. El-Gendy ${ }^{2}$ \\ ${ }^{1}$ Pharmacy Department, University of Malakand, Chakdara, N.W.F.P., Pakistan \\ ${ }^{2}$ Cellulose and Paper Department, National Research Center, Dokki, Cairo, Egypt \\ 3Permanent address: Cellulose and Paper Department, National Research Center, El-Tahrir St., Dokki, Cairo, \\ P.O. 12622, Egypt
}

Received 25 April 2008; accepted in revised form 16 July 2008

\begin{abstract}
The amalgamation of polymer and pharmaceutical sciences led to the introduction of polymer in the design and development of drug delivery systems. Polymeric delivery systems are mainly intended to achieve controlled or sustained drug delivery. Polysaccharides fabricated into hydrophilic matrices remain popular biomaterials for controlled-release dosage forms and the most abundant naturally occurring biopolymer is cellulose; so hdroxypropylmethyl cellulose, hydroxypropyl cellulose, microcrystalline cellulose and hydroxyethyl cellulose can be used for production of time controlled delivery systems. Additionally microcrystalline cellulose, sodium carboxymethyl cellulose, hydroxypropylmethyl cellulose, hydroxyethyl cellulose as well as hydroxypropyl cellulose are used to coat tablets. Cellulose acetate phthalate and hydroxymethyl cellulose phthalate are also used for enteric coating of tablets. Targeting of drugs to the colon following oral administration has also been accomplished by using polysaccharides such as hdroxypropylmethyl cellulose and hydroxypropyl cellulose in hydrated form; also they act as binders that swell when hydrated by gastric media and delay absorption. This paper assembles the current knowledge on the structure and chemistry of cellulose, and in the development of innovative cellulose esters and ethers for pharmaceuticals.
\end{abstract}

Keywords: biopolymers, cellulose derivatives, drug delivery

\section{Introduction}

For many years pharmacists have been employing polymers in every aspect of their work; polystyrene vials, rubber closures, rubber and plastic tubing for injection sets, and polyvinylchloride flexible bags to hold blood and intravenous solutions are all examples of such polymers. The initial use was often restricted to packaging rather than drug delivery. Subsequently, the amalgamation of polymer and pharmaceutical sciences led to the introduction of polymer in the design and development of drug delivery systems.

\subsection{Drug delivery}

Drug delivery is highly innovative in terms of materials to assist delivery, excipients, and technology which allow fast or slow release of drugs. For example analgesics, which often involve as much as five or six tablets a day, can be reduced to a single dose by using appropriate excipients, based on carbohydrate polymers. Polymers are classified in several ways; the simplest classification used for pharmaceutical purposes is into natural and synthetic polymers.

Polysaccharides, natural polymers, fabricated into hydrophilic matrices remain popular biomaterials for controlled-release dosage forms and uses of a hydrophilic polymer matrix is one of the most pop-

*Corresponding author, e-mail: samirki@yahoo.com

(C) BME-PT and GTE 
ular approaches in formulating an extended-release dosage forms [1-3]. This is due to the fact that these formulations are relatively flexible and a well designed system usually gives reproducible release profiles.

Since drug release is the process by which a drug leaves a drug product and is subjected to absorption, distribution, metabolism, and excretion (ADME), eventually becoming available for pharmacologic action, hence drug release is described in several ways as follows:

a) Immediate release refers to the instantaneous availability of drug for absorption or pharmacologic action in which drug products allow drugs to dissolve with no intention of delaying or prolonging dissolution or absorption of the drug.

b) Modified-release dosage forms include both delayed and extended-release drug products. Delayed release is defined as the release of a drug at a time other than immediately following administration, while extended release products are formulated to make the drug available over an extended period after administration.

c) Controlled release includes extended-release and pulsatile-release products. Pulsatile release involves the release of finite amounts (or pulses) of drug at distinct intervals that are programmed into the drug product.

One of the most commonly used methods of modulating tablet drug release is to include it in a matrix system. The classification of matrix systems is based on matrix structure, release kinetics, controlled release properties (diffusion, erosion, swelling), and the chemical nature and properties of employed materials. Matrix systems are usually classified in three main groups: hydrophilic, inert, and lipidic [4]. In addition, the drug release is a function of many factors, including the chemical nature of the membrane, geometry and its thickness, and the particle surface area of the drug device, the physico-chemical nature of the active substance and the interaction between the membrane and the permeating fluids are also important [5-7]. In fact, the mechanism probably varies from membrane to membrane, depending on the membrane structure as well as on the nature of the permeating solution. It is believed that several different mechanisms are involved in the drug release through a non-disintegrating polymer coat [8]: a) Permeation through water-filled pores; in this mechanistic model, the release of the drug involves transfer of the dissolved molecule through water-filled pores. The coating membrane is not homogeneous. The pores can be created by the incorporation of leachable components, such as sugars or incompatible watersoluble polymers into the original coating material [9] or can be produced by an appropriate production process.

b) Permeation through membrane material; in this mechanism, the release process involves the consecutive process of drug partition between the core formulation and the membrane. The drug molecules are dissolved in the membrane at the inner face of the coat, representing equilibrium between a saturated drug solution and the membrane material. The transport of drug across the coat is then driven by the concentration gradient in the membrane. Outside the membrane, the drug is dissolved in an aqueous environment.

c) Osmotic pumping; this release mechanism is driven by a difference in osmotic pressure between the drug solution and the environment outside the formulation.

In addition to the above, controlled release of drug from the matrix is dependent on particle size and type of the polymer wetting, polymer hydration, polymer dissolution, and drug: polymer ratio [1013]. The hydration rate depends on the nature of the constituents, such as the molecular structure and the degree of substitution. The viscosity of the aqueous solution can be increased by increasing the average molecular weight of the polymer, the concentration of the polymer or decreasing the temperature of the solution $[1,14]$. So, the factors associated with polymers, such as molecular weight type (nominal viscosity), concentration, degree of substitution, and particle size [15-22]; have been shown to have a significant influence on drug release. For example, in tablet formulations containing hydrophilic polymers like HPMC, the release of active drug is controlled by the rate of formation of a partially hydrated gel layer of the tablet surface formed upon contact with aqueous gastric media following ingestion and the continuous formation of additional gel layers. In addition to this, process variables like method of granulation, amount of binder added during granulation, 
use of high or low shear mixer, granule size distribution, compression force during tableting, etc., are also important for extended-release [23-33].

\subsection{Cellulose and cellulosics}

Cellulose is the most abundant naturally occurring biopolymer [34, 35]. Various natural fibers such as cotton and higher plants have cellulose as their main constituent $[36,37]$. It consists of long chains of anhydro-D-glucopyranose units (AGU) with each cellulose molecule having three hydroxyl groups per AGU, with the exception of the terminal ends (Figure 1). Cellulose is insoluble in water and most common solvents [35]; the poor solubility is attributed primarily to the strong intramolecular and intermolecular hydrogen bonding between the individual chains [34]. In spite of its poor solubility characteristics, cellulose is used in a wide range of applications including composites, netting, upholstery, coatings, packing, paper, etc. Chemical modification of cellulose is performed to improve process ability and to produce cellulose derivatives (cellulosics) which can be tailored for specific industrial applications [38]. Cellulosics are in general strong, reproducible, recyclable and biocompatible [39], being used in various biomedical applications such as blood purification membranes and the like. Thus, through derivatization, cellu- losics have opened a window of opportunity and have broadened the use of cellulosics.

As shown in the molecular structure represented in Figure 1, the hydroxy groups of $\beta$-1,4-glucan cellulose are placed at positions $\mathrm{C}_{2}$ and $\mathrm{C}_{3}$ (secondary, equatorial) as well as $\mathrm{C}_{6}$ (primary). The $\mathrm{CH}_{2} \mathrm{OH}$ side group is arranged in a trans-gauche $\left(t_{g}\right)$ position relative to the $\mathrm{O}_{5}-\mathrm{C}_{5}$ and $\mathrm{C}_{4}-\mathrm{C}_{5}$ bonds. As a result of the supramolecular structure of cellulose, the solid state is represented by areas of both high order (crystalline) and low order (amorphous). The degree of crystallinity (DP) of cellulose (usually in the range of 40 to $60 \%$ ) covers a wide range and depends on the origin and pretreatment of the sample (Table 1). The morphology of cellulose has a profound effect on its reactivity, the hydroxyl groups located in the amorphous regions are highly accessible and react readily, whereas those in crystalline regions with close packing and strong interchain bonding can be completely inaccessible [40]. Cellulose that is produced by plants is referred to as native cellulose, which is found in two crystalline forms, cellulose I and cellulose II [41]. Cellulose II, generally occurring in marine algae, is a crystalline form that is formed when cellulose $\mathrm{I}$ is treated with aqueous sodium hydroxide [42-44]. Among the four different crystalline polymorphs cellulose I, II, III, and IV, cellulose I is thermodynamically less stable while cellulose II is the most

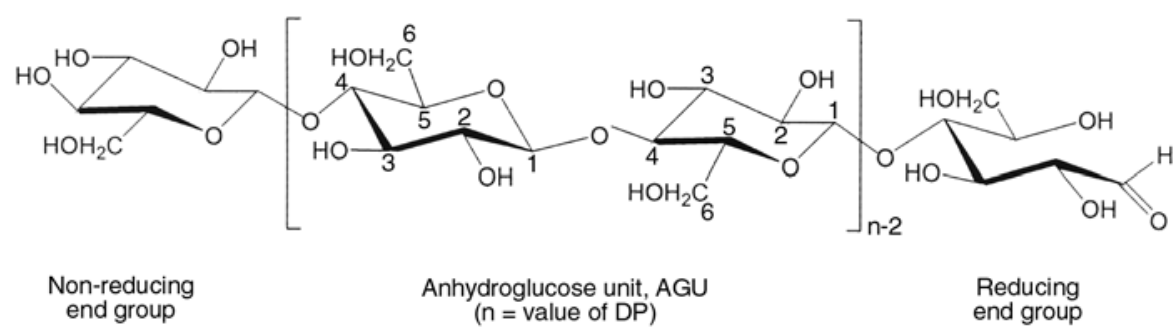

Figure 1. Molecular structure of cellulose



Figure 2. Transformation of cellulose into its various polymorphs

Table 1. Average DP of cellulose obtained from different sources. (Reprinted from reference [39].)

\begin{tabular}{|c|c|c|c|c|c|c|c|c|c|}
\hline Source & Wood & Valonia & Cotton & Acetobacter xylinum & Cotton linters & Flax & Pulp & Kapok & Ramie \\
\hline${ }^{*} \mathrm{DP}_{\mathrm{w}}\left(10^{3}\right)$ & $8-9$ & $25-27$ & $8-15$ & $2-6$ & $1-5$ & $7-8$ & 2.1 & 9.5 & $9-11$ \\
\hline
\end{tabular}

${ }^{*} \mathrm{DP}_{\mathrm{w}}$ weight average DP determined by viscometric methods 
stable structure. A liquid ammonia treatment of cellulose I and cellulose II gives crystalline cellulose III form [45-47], and the heating of cellulose III generates cellulose IV crystalline form [48]. Figure 2 shows the transformation of cellulose into its various polymorphs [49].

\section{Chemical modification of cellulose}

The typical modifications of cellulose are esterifications and etherifications at the hydroxyl groups of cellulose. Most water-soluble and organic solvent-soluble cellulose derivatives are prepared by these substitution reactions, and drastic changes in the original properties of cellulose can usually be achieved by these chemical modifications. Others are ionic and radical grafting, acetalation, deoxyhalogenation, and oxidation. Figure 3 shows schematic representation of position in cellulose structure for chemical modifications [38].

\subsection{Oxidation}

Oxidized celluloses (or oxycelluloses) are water insoluble materials produced by reacting cellulose with an oxidant such as gaseous chlorine, hydrogen peroxide, peracetic acid, chlorine dioxide, nitrogen dioxide (dinitrogen tetraoxide), persulfates, permanganate, dichromate-sulfuric acid, hypochlorous acid, hypohalites or periodates. These oxidized celluloses may contain carboxylic, aldehyde, and/or ketone functionalities, in addition to the hydroxyl groups, depending on the nature of the oxidant and the reaction conditions used in their preparation [50].

It is well known that primary alcohol groups of cellulose are partly converted to carboxyl ones by oxidation with $\mathrm{N}_{2} \mathrm{O}_{4}$ in chloroform. Recently a new water-soluble reagent, 2,2,6,6-tetramethylpiperidine-1-oxyl radical (TEMP) can oxidize primary alcohol groups of water soluble polysaccharides such as starch to carboxyl ones with good yields and selectivity in the presences of an oxidizing agent at $\mathrm{pH} 9-11$ [51]. The TEMPO-NaBr-NaClO system was first applied to native cellulose by Chang and Robyt [52] but did not give water-soluble cello-uronic acid. By oxidation of cellulose under various condition and using regenerated and mercerized celluloses as starting materials, small amounts of carboxyl groups were introduced into

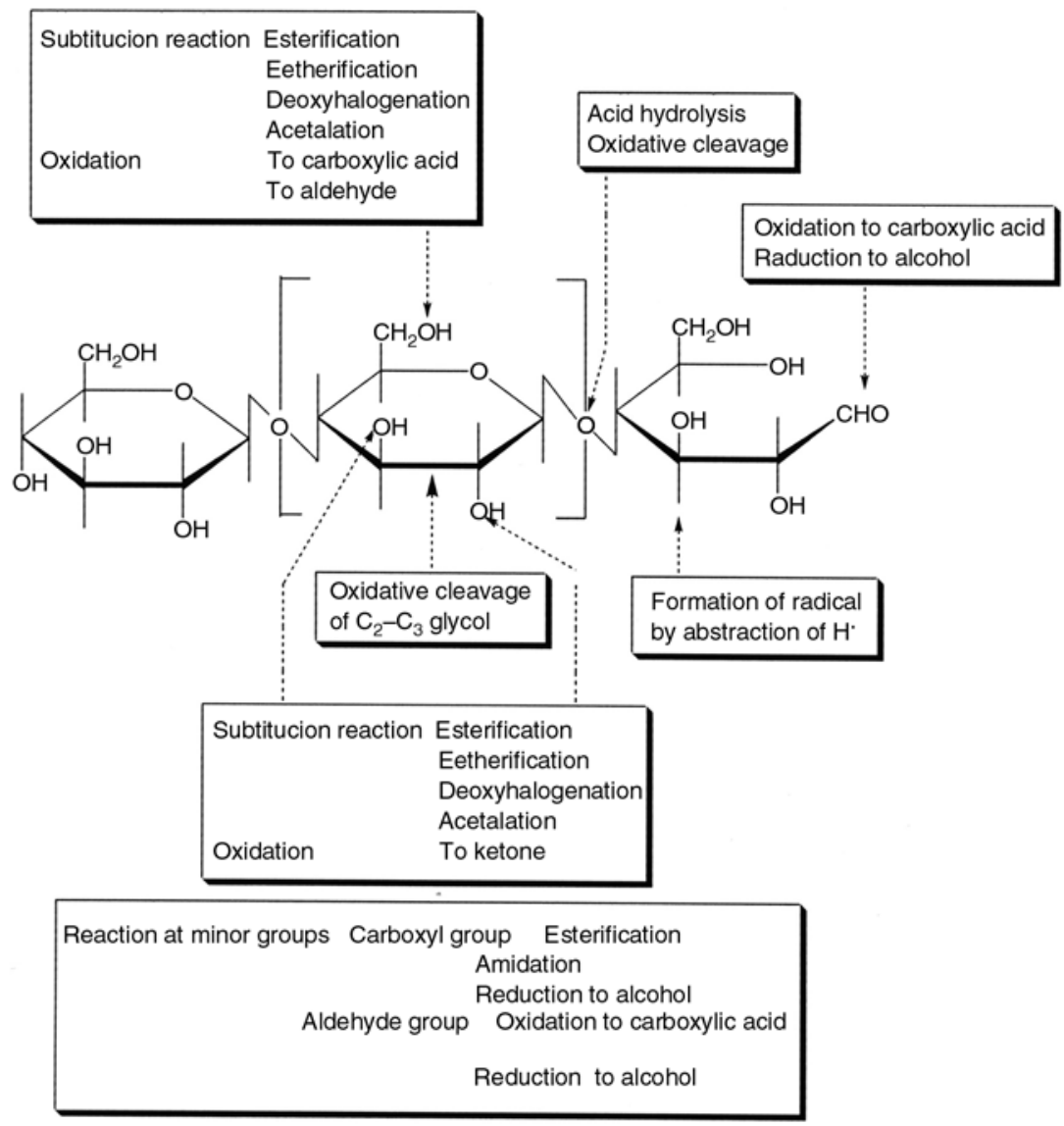

Figure 3. Position in cellulose structure for chemical modifications 
cellulose by this oxidation and water soluble cellourionic acid sodium salts were obtained [53]. On the other hand, the periodate oxidation is used to prepare dialdehyde cellulose at laboratory levels which proceeded homogeneously in the aqueous solution, and almost completely oxidized dialdehyde cellulose was obtained within $20 \mathrm{~h}$ [54]. This dialdehyde cellulose can be oxidized to the corresponding dicarboxyl cellulose with sodium chlorite, or reduced to the corresponding dialcohol cellulose with sodium borohydride $[55,56]$.

\subsection{Microcrystallization}

Purified microcrystalline cellulose is partially depolymerized cellulose prepared by treating $\alpha$-cellulose, obtained as a pulp from fibrous plant material, with mineral acids. The degree of polymerization is typically less than 400 . Traditionally, MCC has been prepared from bamboo $[57,58]$, wood pulp [59], viscose rayon [60] and cotton [61]. Attempts have also been made to produce MCC from other sources such as newsprint waste [62], hosiery waste [63], and corncobs [64], as well as from fast-growing plants including sesbania sesban, sroxburghii, crotalaria juncea [65], bagasse, rice straw, as well as cotton stalks bleached pulps [66]. When cellulose reacts with acid, the $\beta(1-4)$ glycoside bond is attacked and the acetal linkage is broken resulting in the hydrolysis of the chain, thus the degree of polymerization decreases [67]. On the other hand, oxidizing agents have an impacting effect on the cellulose chain and the hydroxyl groups react to form carbonyl and carboxyl groups. So, the oxidation reaction of cellulose shortens the average length of the cellulose chain and using of $\mathrm{HNO}_{3}$ or $\mathrm{N}_{2} \mathrm{O}_{4}$, each of which transfer cellulose into MCC with carboxyl groups [68].

\subsection{Etherification}

The presence of hydroxyl groups readily suggested to chemists that cellulose might be converted to useful derivatives by etherification. This reaction is expressed by the Equation (1):

$\mathrm{ROR}+\mathrm{R}^{\prime} \mathrm{Cl} \rightarrow \mathrm{ROR}^{\prime}+\mathrm{HCl}$

alcohol alkylchloride ether hydrogen cloride

where $\mathrm{R}^{\prime}$ is an organic radical such as the methyl $\left(\mathrm{CH}_{3}-\right)$, ethyl $\left(\mathrm{C}_{2} \mathrm{H}_{5-}-\right)$, or a more complex structure. The alcohol, $\mathrm{ROH}$, represents one of the three $\mathrm{OH}$ groups in an AGU. Cellulose ethers can be prepared by treating alkali cellulose with a number of various reagents including alkyl or aryl halides (or sulfates), alkene oxides, and unsaturated compounds activated by electron-attracting groups. For example methyl and ethylcellulose ethers can be prepared by the action of methyl and ethyl chlorides or methyl and ethyl sulfates, respectively, on cellulose that has been treated with alkali. Purification is accomplished by washing the reaction product with hot water. The degree of methylation or ethylation can be controlled to yield products that vary in their viscosities when they are in solution. If mixed ether such as ethylhydroxyethyl cellulose is to be produced, the two reagents, ethyl chloride and ethylene oxide, can be added either consecutively or as a mixture. The nature of the resultant product is dependent upon the molar ratio of the two etherifying agents (the ratio of the number of molecules of one to the other) and on the method of their addition. Table 2 provides a list of some typical reagents, co-products, and by-products.

On the other hand, cellulose ethers of moderate to high molecular weight are insoluble in water. As a rule, as the DS increases, the polymers gradually pass through a stage of solubility in dilute alkali

Table 2. Etherifying agents, co-products, and by-products from the production of cellulose ethers

\begin{tabular}{|c|c|c|c|c|}
\hline \multirow{2}{*}{ Cellulose ether } & \multirow{2}{*}{ Etherifying agent } & \multirow{2}{*}{ Co-product } & \multicolumn{2}{|c|}{ By-product } \\
\hline & & & Name & Formula \\
\hline Methyl (MC) & methyl chloride & $\mathrm{NaCl}$ & $\begin{array}{l}\text { methanol } \\
\text { dimethyl ether }\end{array}$ & $\begin{array}{l}\mathrm{CH}_{3} \mathrm{OH} \\
\mathrm{CH}_{3} \mathrm{OCH}_{3}\end{array}$ \\
\hline Ethyl (EC) & ethyl chloride & $\mathrm{NaCl}$ & $\begin{array}{l}\text { ethanol } \\
\text { diethyl ether }\end{array}$ & $\begin{array}{l}\mathrm{C}_{2} \mathrm{H}_{5} \mathrm{OH} \\
\mathrm{C}_{2} \mathrm{H}_{5} \mathrm{OC}_{2} \mathrm{H}_{5}\end{array}$ \\
\hline Hydroxyethyl (HEC) & ethylene oxide & none & $\begin{array}{l}\text { ethylene glycol and } \\
\text { polymers thereof }\end{array}$ & $\mathrm{CH}_{2} \mathrm{OHCH}_{2} \mathrm{OH}$ \\
\hline Hydroxypropyl (HPC) & propylene oxide & none & $\begin{array}{l}\text { propylene glycol and } \\
\text { polymers thereof }\end{array}$ & $\mathrm{CH}_{3} \mathrm{CH}_{2} \mathrm{OHCH}_{2} \mathrm{OH}$ \\
\hline Carboxymethyl (CMC) & chloroacetic acid & $\mathrm{NaCl}$ & glycolic acid & $\mathrm{HO}-\mathrm{CH}_{2}-\mathrm{COOH}$ \\
\hline
\end{tabular}


Table 3. Solubility of cellulose ether (organic solvent is a mixture of chloroform or methylene chloride and methanol or ethanol)

\begin{tabular}{|c|c|c|}
\hline Cellulose ether & DS & Solubility \\
\hline \multirow{3}{*}{$\mathrm{MC}$} & $0.1-1.1$ & soluble in $6-8 \% \mathrm{NaOH}$ \\
\hline & $1.4-2.0$ & soluble in $\mathrm{H}_{2} \mathrm{O}$ \\
\hline & $2.4-2.8$ & soluble in organic solvents \\
\hline \multirow{2}{*}{$\mathrm{EC}$} & $0.8-1.7$ & soluble in $\mathrm{H}_{2} \mathrm{O}$ \\
\hline & $2.4-2.8$ & soluble in organic solvents \\
\hline $\mathrm{NaCMC}$ & $0.1-3.0$ & soluble in $\mathrm{H}_{2} \mathrm{O}$ \\
\hline $\mathrm{CMC}$ & $0.05-0.25$ & soluble in $6-8 \% \mathrm{NaOH}$ \\
\hline \multirow{2}{*}{ HEC } & $0.11-0.31$ & soluble in $6-8 \% \mathrm{NaOH}$ \\
\hline & $0.66-1.66$ & soluble in $\mathrm{H}_{2} \mathrm{O}$ \\
\hline \multirow{2}{*}{$\mathrm{HPC}$} & $0.15-0.35$ & soluble in $6-8 \% \mathrm{NaOH}$ \\
\hline & $3.5-4.5$ & soluble in $\mathrm{H}_{2} \mathrm{O}$ \\
\hline \multirow{3}{*}{ EHEC [70] } & 0.68 (ethyl) and 0.87 (hydroxyethyl) & soluble in $\mathrm{H}_{2} \mathrm{O}$ \\
\hline & 1.9-2.2 (ethyl) and 0.35-0.65 (hydroxyethyl) & soluble in organic solvents \\
\hline & 1.33 (ethyl) and 0.51 (hydroxyethyl) & soluble in both $\mathrm{H}_{2} \mathrm{O}$ and organic solvents \\
\hline
\end{tabular}

(those with a DS of up to about 1.0), then through a water soluble stage (about DS 1.0-2.3), and finally attain an organic-solvent-soluble stage (DS 2.3-3.0) such DS ranges are, of course, only approximate. Also, the trend toward organic solvent solubility is gradual and differs for individual ethers. The ionic character of $\mathrm{CMC}$, for example, makes its behavior exceptional. Moreover, the uniformity of substitution along the cellulose chain can have a major influence on solubility [69]. Solubility of some typical cellulose ether is summarized in Table 3. The ranges of DS cited in these examples are only approximate because solubility is influenced by the distribution of molecular weights of various fractions in a given product and by the extent and uniformity of substitution within particular products or molecular weight fractions. The water-soluble cellulose ethers should not be regarded simply as water-soluble forms of cellulose. The ethers are derivatives of cellulose, containing only a fraction of the original cellulose structure in their molecular make-up [70].

\subsection{Esterification}

The esterification can be considered as a typical equilibrium reaction in which an alcohol and acid react to form ester and water. Cellulose is esterified with certain acids such as acetic acid, nitric acid, sulfuric acid, and phosphoric acid. A prerequisite is that the acid used can bring about a strong swelling thus penetrating throughout the cellulose structure. Esterification of cellulose to give cellulose trinitrate was discovered by Schonbein in 1846 using a mixture of sulfuric and nitric acids. The resultant compound was so flammable that its first use was as smokeless gunpowder. By the end of the nineteenth century, cellulose nitrates had been prepared with a lower DS, and they could safely be used for other purposes. All cellulose nitrates are prepared by Schonbein's method, in which aqueous slurry of cellulose is reacted with nitric acid in the presence of sulfuric acid. The reaction is in equilibrium and thus the removal of water during the reaction forces the reaction to completion and the relative concentrations of the reacting species determine the ultimate DS [71].

The discovery that cellulose esters could be prepared with organic substituents led to the development of cellulose derivatives that had decreased flammability compared to that of cellulose nitrate. The most important organic ester is cellulose acetate which prepared by the reaction of acetic anhydride with cellulose in the presence of sulfuric acid. Acetic acid is used as the solvent and the reaction is carried out for about $8 \mathrm{~h}$ to yield the triester (defined as having a DS greater than 2.75). The derivatives with lower DS values are obtained by the hydrolysis of the triester by hydrochloric acid to yield the desired substitution.

\section{Pharmaceutical uses of cellulose and cellulose derivatives}

\subsection{Oxycellulose}

Oxidized cellulose (oxycellulose) is cellulose in which some of the terminal primary alcohol groups of the glucose residues have been converted to car- 
boxyl groups. Therefore, the product is possibly a synthetic polyanhydrocellobiuronide and that contain $25 \%$ carboxyl groups are too brittle (friable) and too readily soluble to be of use. Those products that have lower carboxyl contents are the most desirable.

The oxidized cellulose fabric, such as gauze or cotton, resembles the parent substance; it is insoluble in water and acids but soluble in dilute alkalis. In weakly alkaline solutions, it swells and becomes translucent and gelatinous. When wet with blood, it becomes slightly sticky and swells, forming a dark brown gelatinous mass. So, it is used in various surgical procedures, by direct application to the oozing surface except when used for homeostasis, it is not recommended as a surface dressing for open wounds [72].

The oxidized cellulose product readily disperses in water and forms thixotropic dispersions. Such suspensions/dispersions, which may be optionally combined with other pharmaceutical and cosmetic adjuvants, can be used for producing novel filmforming systems. A wide variety of solid (crystalline or amorphous) and liquid (volatile or non-volatile) acidic, neutral, and basic bioactive compounds can be entrapped/loaded in such systems, thereby producing substantive controlled and/or sustained release formulations, having unique applications in the development of variety of cosmetic, pharmaceutical, agricultural, and consumer products. Topical formulations (cream, lotion, or spray) prepared using the oxidized cellulose material, are bioadhesive, can be applied on the human skin or hair, can be included in cosmetics [73]. Oxidized cellulose dispersion uses in antiacne cream, anti-acne lotion, sunscreen spray, anti-fungal cream also.

For using oxidized cellulose as a direct compression excipient Banker and Kumar grounded it and prepared tablets by mixing the ingredients by ratio of 20,79 and $1 \%$ for oxidized cellulose, lactose NF (Fast-Flo), magnesium stearate respectively, each tablet weighed $500 \pm 10 \mathrm{mg}$. The hardness, the disintegration times and water penetration rate were $5.17 \mathrm{~kg}, 30 \mathrm{sec}$ and $10.49 \mathrm{mg} / \mathrm{sec}$ respectively [73].

\subsection{Microcrystalline cellulose}

Since its introduction in the 1960s, MCC has offered great advantages in the formulation of solid dosage forms, but some characteristics have limited its application, such as relatively low bulk density, moderate flowability, loss of compactibility after wet granulation, and sensitivity to lubricants. Silicification of MCC improves the functionality of MCC with such properties as enhanced density, low moisture content, flowability, lubricity, larger particle size, compactibility and compressibility. Silicified MCC (SMCC) is manufactured by codrying a suspension of MCC particles and colloidal silicon dioxide such that the dried finished product contains $2 \%$ colloidal silicon dioxide [74]. Silicon dioxide simply adheres to the surface of MCC and occurs mainly on the surface of MCC particles; only a small amount was detected in the internal regions of the particles. So, SMCC shows higher bulk density than the common types of MCC [75]. Also, tensile strength of compacts of SMCC is greater than that of the respective MCC [76] and it is most probably a consequence of intersurface interactions of silicon dioxide and MCC [77].

Tableting studies have suggested that SMCC has enhanced compactibility, even after wet granulation, and reduced lubricant sensitivity, compared to the regular grade of MCC.

For example, Sherwood and Becker [78] have compared the direct-compression tableting performance of SMCC 90 with a regular grade of MCC (Avicel PH102) that has similar particle size and density. They found that, SMCC 90 was $10-40 \%$ more compactable than regular MCC in the absence of drug. The SMCC 90 also showed a lower lubricant sensitivity and retained, two to three times the compactibility in tableting of the comparable MCC grade in a blending time study. Also, Guo and Augsburger compared SMCC's performance to that of other excipients commonly used in hard gelatin capsule direct-fill formulations such as anhydrous lactose (direct tableting grade), pregelatinized starch (PGS), and MCC. The study revealed that SMCC exhibited relatively higher compactibility under the low compression force of a donator capsule filling than either PGS or lactose. Products formulated with the SMCC materials exhibited faster dissolution rates than those formulated with PGS and anhydrous lactose when loaded with 5\% piroxicam, 30 and 50\% acetaminophen. Such higher compactibility and fast dissolution rates suggest that SMCC could be a suitable alternative excipient for direct- fill formulations for hard shell 
capsules [79]. In another study, comparison of the compaction force versus tablet tensile strength showed that SMCC was approximately $20 \%$ more compactible than regular MCC. Stronger tablets manufactured from SMCC were easier to coat further also, the size and weight of individual tablets were decreased, which increases patients' compliance [80]. SMCC possesses further advantages, decreasing the hygroscopicity of the active ingredient (increased stability of tablets). Due to a decreased size, higher compressibility, and better flow properties (lower sensitivity to the rate of tableting); a larger number of tablets in one batch can be achieved, which makes their manufacture substantially cheaper [81].

In contrast to routinely used SMCC, the high-density degree showed further improvement in flow properties and lesser sensitivity to the rate of tableting. Muzíková and Nováková compare the tensile strength and disintegration time of compacts from two types of SMCC, Prosolv SMCC 90, and Proslov HD 90 high density SMCC [82]. The used lubricants were magnesium stearate and sodium stearyl fumarate in a concentration of $0.5 \%$, while ascorbic acid and acetylsalicylic acid in a concentration of $50 \%$ were used as active ingredients. They found that; SMCC proved to be better compatible than high density SMCC; the compacts were of higher strength, which was markedly increased with increasing compression force. High density SMCC was more sensitive to additions of lubricants, and a greater decrease in strength was recorded due to the influence of sodium stearyl fumarate. The disintegration time of compacts from high density SMCC without as well as with lubricants was shorter than that of those from SMCC and was increasing with increasing compression force.

\subsection{Cellulose ether}

Cellulose ethers are widely used as important excipients for designing matrix tablets. On contact with water, the cellulose ethers start to swell and the hydrogel layer starts to grow around the dry core of the tablet. The hydrogel presents a diffusional barrier for water molecules penetrating into the polymer matrix and the drug molecules being released [83-87].

\subsubsection{Sodium carboxymethyl cellulose}

It is a low-cost commercial soluble and polyanionic polysaccharide derivative of cellulose that has been employed in medicine, as an emulsifying agent in pharmaceuticals, and in cosmetics [88]. The many important functions provided by this polymer make it a preferred thickener, suspending aid, stabilizer, binder, and film-former in a wide variety of uses. A representative listing of the many applications for $\mathrm{NaCMC}$ is given below in Table 4 [89].

In biomedicine it has been employed for preventing postsurgical soft tissue and epidural scar adhesions. Sanino et al. have proposed the use of CMC and HEC-based gels as water absorbents in treating edemas [90]. It can also be used for the therapeutic application of the superoxide dismutase enzyme (SOD), presented as hydrogels of CMC carrying the enzyme for its controlled release [91]. Therapeutic use of SOD enzyme is limited by its fast clearance from the bloodstream and inactivation by its own reaction product, i.e. hydrogen peroxide. The SOD enzyme was adsorbed into the hydrogel for its controlled release, rendering two formulations: SOD-CMC conjugates and SOD-CMC hydrogels [92]. Both formulations were chemically and biologically characterized, the resulting showed that up to $50 \%$ of the SOD was released from the

Table 4. Applications for NaCMC

\begin{tabular}{|l|l|}
\hline \multicolumn{1}{|c|}{ Specific applications } & \multicolumn{1}{c}{ Properties utilized } \\
\hline Ointments, creams, lotions & emulsion, stabilizer, thickener, film-former \\
\hline Jellies, salves & thickener, gelling agent, protective colloid, film-former \\
\hline Tablet binder, granulation aid & high-strength binder \\
\hline Sustained release & thickener, diffusion barrier \\
\hline Tablet coating & film-former \\
\hline Bulk laxatives & physiologically inert, high water-binding capacity \\
\hline Syrups, suspensions & thickener, suspending aid \\
\hline Toothpaste & thickener, flavor stabilizer, suspending aid, binder \\
\hline Shampoos, foamed products & suspending aid, thickener, foam stabilizer, high water-binding capacity \\
\hline Denture adhesives & wet tack, long-lasting adhesion \\
\hline
\end{tabular}


SOD-CMC hydrogel after $72 \mathrm{~h}$, indicating a controlled release kinetic [93].

In a double-blind trial in patients suffering from Sjogren's syndrome, a CMC-containing substitute and a glycerine mouthwash used as a control were tested. Nocturnal oral discomfort was the only symptom which was relieved more by the CMCcontaining substitute [94]. And in comparing the lubricating properties of two saliva substitutes, one containing mucin and the other CMC both showed almost the same objective effects, with changed friction values of about 15 min which was more than twice as long as for water. Both water and the two saliva substitutes relieved the symptoms of dry mouth to some extent but they did not have a sufficiently long lasting effect [95].

Also, $\mathrm{NaCMC}$ can be used in preparation of semiinterpenetrating polymer network microspheres by using glutaraldehyde as a crosslinker. Ketorolac tromethamine, an anti-inflammatory and analgesic agent, was successfully encapsulated into these microspheres and drug encapsulation of up to $67 \%$ was achieved. The diffusion coefficients decreased with increasing crosslinking as well as increasing content of $\mathrm{NaCMC}$ in the matrix and in vitro release studies indicated a dependence of release rate on both the extent of crosslinking and the amount of NaCMC used to produce microspheres [96]. Another nonsteroidal anti-inflammatory agent indomethacin, has a short biological half-life of 2.6-11.2 $\mathrm{h}$ [97], the usual oral dosage for adults is 25 or $50 \mathrm{mg}, 2$ to 3 times a day. Controlled release preparations of this drug are to increase patient compliance and to reduce adverse effects, fluctuation in plasma concentration and dosing frequency. Waree and Garnpimol prepared a complex of chitosan and CMC and crosslinked by glutaraldehyde to control the release of indomethacin from microcapsule [98]. The membrane of microcapsules was formed by electrostatic interaction between positive charged amine on the chitosan chain and the negative charged hydroxyl group on the CMC chain, the concentration of CMC affect on the formability of chitosan-CMC microcapsules [99]. Glutaraldehyde reacted with hydroxyl group in CMC chain to form acetal and reacted with amino group in chitosan to form Schiff base. The crosslinking provided dense and rigid surface of microcapsule and reduced the degree of swelling and the rate of drug release microcapsule. In the drug release study, the mechanism of drug release was prominently diffusion controlled through wall membrane and pore. The release of drug from microcapsule could be governed by optimizing the $\mathrm{pH}$ of chitosan solution, the hardening time and the glutaraldehyde content [100-103].

Esterification of NaCMC with acryloyl chloride improves the swelling properties such as the degree of swelling of the esterified product changes as the $\mathrm{pH}$ is varied. At $\mathrm{pH} 9.4$ the swelling \% is quite high compared to that at $\mathrm{pH} 1.4$ and 5.4 so; it can be used as a $\mathrm{pH}$ responsive polymer for various biomedical applications. Since this polymer swells at high $\mathrm{pH}$ and collapses at low $\mathrm{pH}$ values so; this polymer can be used in oral delivery, in which the polymer will retard drug release at low $\mathrm{pH}$ values in the stomach while releasing the same at high $\mathrm{pH}$ values in the small intestine [104]. Hence this polymer can be used for $\mathrm{pH}$-sensitive drug delivery system like asprin, indomethacin, diclofenac etc. in the intestine and as a wound dressing material [105].

\subsubsection{Methylcellulose}

$\mathrm{MC}$ resembles cotton in appearance and is neutral, odorless, tasteless, and inert. It swells in water and reproduces a clear to opalescent, viscous, colloidal solution and it is insoluble in most of the common organic solvents. However, aqueous solutions of $\mathrm{MC}$ can be diluted with ethanol. MC solutions are stable over a wide range of $\mathrm{pH}$ (2 to 12) with no apparent change in viscosity. They can be used as bulk laxatives, so it can be used to treat constipation, and in nose drops, ophthalmic preparations, burn preparations ointments, and like preparations. Although MC when used as a bulk laxative takes up water quite uniformly, tablets of MC have caused fecal impaction and intestinal obstruction [72]. As we mention before; it dissolves in cold water but higher DS-values result in lower solubility, because the polar hydroxyl groups are masked so; the expected questions are, how drug works and how it is given? MC absorbs water, which expands in the intestines, when eaten MC is not absorbed by the intestines but passes through the digestive tract undisturbed. It attracts large amounts of water into the colon, producing a softer and bulkier stool so; it is used to treat constipation, diverticulosis, hemorrhoids and irritable bowel syndrome. It should be taken with sufficient amounts of fluid to prevent 
dehydration. The commons side effect is nausea and the less common side effects are vomiting and cramp [106].

On the other hand, solid dispersion, in which compounds are dispersed into water-soluble carriers, has been generally used to improve the dissolution properties and the bioavailability of drugs that are poorly soluble in water [107-111]. MC has the hydroxyl group in a structure and is interactive with the carboxylic acid of carboxyvinyl polymer (CP), as well as poly(ethylene oxide) (PEO). Ozeki et al. examined the controlled release of antipyretic phenacetin (PHE) from solid dispersion by the formation of an interpolymer complex between $\mathrm{MC}$ and $\mathrm{CP}$. They found that, the rate of PHE release from the solid dispersion granules was lower than from the PHE powder. The PHE release profiles from the solid dispersion granules varied depending on the $\mathrm{MC} / \mathrm{CP}$ ratio, and the rate of release was the lowest at a MC/CP ratio of 50:50. Also the rate of PHE release decreased as the molecular weight of MC increased. By studying the effect of the molecular weight of $\mathrm{MC}$ on the time required to release half of PHE $\left(T_{50}\right)$. The $T_{50}$ of the MC-CP solid dispersion increased as the molecular weight of the MC increased, and it essentially leveled off when the molecular weight of MC was 180000 (Figure 4). So, from this study it is feasible to control the release of PHE from MC-CP polymer solid dispersion granules by modulating complex formation between $\mathrm{MC}$ and $\mathrm{CP}$, which can be accomplished by altering the $\mathrm{MC} / \mathrm{CP}$ ratio and the molecular weight of MC [112].

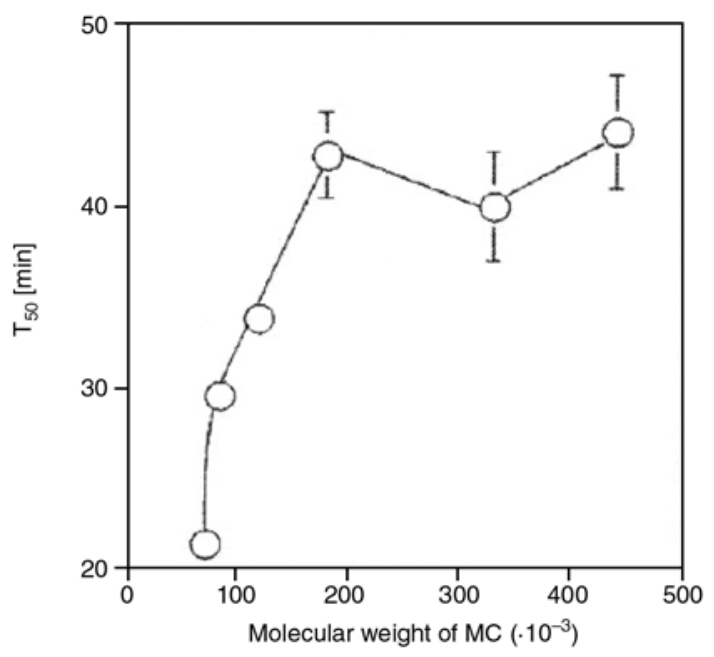

Figure 4. $\mathrm{T}_{50}$ for PHE release from MC-CP solid dispersion using various molecular weights of $\mathrm{MC}$

\subsubsection{Ethylcellulose}

It is the non-ionic, $\mathrm{pH}$ insensitive cellulose ether and insoluble in water but soluble in many polar organic solvents. It is used as;

- A non-swellable, insoluble component in matrix or coating systems.

- When water-soluble binders cannot be used in dosage processing because of water sensitivity of the active ingredient, EC is often chosen.

- It can be used to coat one or more active ingredients of a tablet to prevent them from reacting with other materials or with one another.

- It can prevent discoloration of easily oxidizable substances such as ascorbic acid.

- Allowing granulations for easily compressed tablets and other dosage forms.

- It can also be used on its own or in combination with water-soluble polymers to prepare sustained release film coatings that are frequently used for the coating of micro-particles, pellets and tablets. In addition to EC, HEC is also non-ionic water-soluble cellulose ether, easily dispersed in cold or hot water to give solutions of varying viscosities and desired properties, yet it is insoluble in organic solvents. It is used as a modified release tablet matrix, a film former and a thickener, stabilizer and suspending agent for oral and topical applications when a non-ionic material is desired. Many researchers like Mura et al. [113] Friedman and Golomb [114] Soskolne et al. [115] have demonstrated the ability of EC to sustain the release of drugs.

\subsubsection{Hydroxypropyl cellulose}

It is non-ionic water-soluble and $\mathrm{pH}$ insensitive cellulose ether. It can be used as thickening agent, tablet binding, modified release and film coating. By using solid dispersions containing a polymer blend, such as HPC and EC, it is possible to precisely control the rate of release of an extremely water soluble drug, such as oxprenolol hydrochloride [116-120] In this case, the water-soluble HPC swells in water and is trapped in the water-insoluble EC so that the release of the drug is slowed. These studies have shown that there is a linear relationship between the rate of release of the water insoluble drug and its interaction with the polymer [121-123]. On the other hand, Buccal delivery formulations containing HPC and polyacrylic acid 

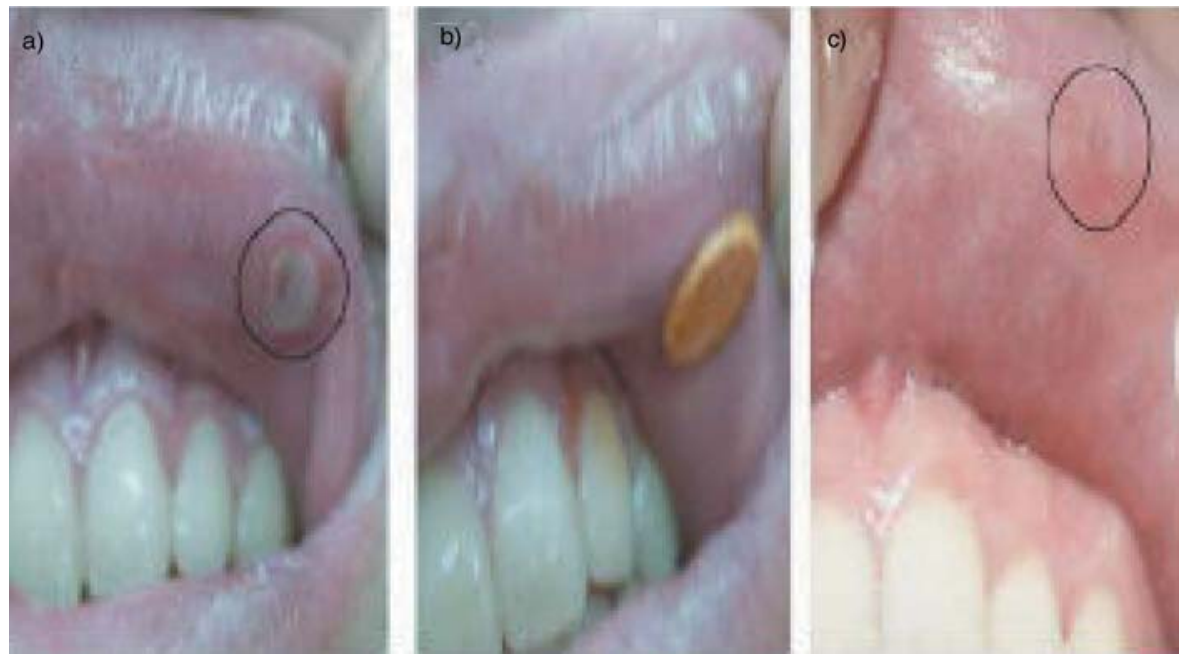

Figure 5. Treatment of a 12-year-old male patient with the bioadhesive tablet. (a) $7 \mathrm{~mm}$ diameter aphthous lesion on the mucosal membrane. (b) 15 minutes after placement of tablet onto the canker sore. (c) After $36 \mathrm{~h}$.

have been in use for many years [124-128], with various ratios of the two polymers. Whereas mucoadhesive delivery systems have been reported for several different drugs [129-131], there have been only a few reports about their use in the treatment of oral mucosal disorders such as canker sores. Adhesive tablets were prepared by compression molding of mixed powders of crosslinked polyacrylic acid and HPC, absorbed with citrus oil and magnesium salt. Tablets adhere well to the mucosal tissue and gradually erode for $8 \mathrm{~h}$ releasing the citrus oil whereas the magnesium is released during a period of $2 \mathrm{~h}$. Both experimental and plain tablets were effective in reducing pain and decreasing healing time without adverse side effects, and the tablets loaded with active agents were more effective [132]. Figure 5 shows a male who had recurrent aphthous stomatitis, with a $7 \mathrm{~mm}$ diameter canker sore in the left lip before, during, and after treatment with the mucoadhesive tablet.

To obtain a new biocompatible polymeric materials of high molecular weight with a range of hydrophilic and swelling properties, as well as chemical and mechanical ones [133] hydroxypropyl methacrylate was grafted onto hydroxypropyl starch and HPC by Ce(IV) redox initiation method and crosslinked by different amounts of ethyleneglycol dimethacrylate. The graft copolymers can be considered of great interest as direct compression excipients due to their different chemical structure and composition; they showed differences in viscoelastic properties that revealed an interesting range of possibilities for use in drug delivery for- mulations [134]. Although no crosslinked polymer was suitable as a direct compression excipient, rheological studies suggested that the use of this kind of graft copolymer in a formulation could improve the controlled release properties. Furthermore, noncrosslinked graft copolymers of hydroxypropyl methacrylate on both hydroxypropyl starch and HPC offer interesting characteristics as controlled release matrices. Gon et al. observed that when excipients were added, performance (compressional and tablet parameters and dissolution tests) of the tablets was negatively affected. Therefore, graft copolymers can stand alone as an effective matrix for tablets designed for drug delivery systems [135].

\subsubsection{Hydroxypropyl methyl cellulose}

HPMC is water soluble cellulose ether and it can be used as hydrophilic polymer for the preparation of controlled release tablets. Water penetrates the matrix and hydrating the polymer chains which eventually disentangle from the matrix. Since it is generally recognized that drug release from HPMC matrices follows two mechanisms, drug diffusion through the swelling gel layer and release by matrix erosion of the swollen layer [136-139], therefore, quantifying the percent contribution of diffusion and erosion to the overall drug release is important. Several authors [140-142] have attempted to model the erosion mechanism of swellable polymeric matrices. Reynolds et al. found that; drug release resulting from polymer erosion was linear versus 
time and was found to be a function of the number average molecular weight of the polymer (HPMC). In contrast, by comparing the diffusional release rates of HPMC of different molecular weight, they found that, they were independent of number average molecular weight of the polymers studied. The erosion study indicated that polymer diffusion of the HPMC polymer chains through the aqueous diffusion layer was the rate-limiting step for polymer erosion and in general polymer erosion was found to be inversely related to the polymer number average molecular weight [143]. In addition, surface area/volume is one of the key variables in controlling drug release from HPMC matrix tablets. It can be utilized to duplicate drug release profiles for tablets having different sizes, shapes, and dose levels. Tablets having the same surface area but different surface area/volume values did not result in similar drug release; tablets with larger surface area/volume values had faster release profiles [144].

Another variable in controlling drug release is the viscosity of HPMC. Ifat Katzhendler et al. studied the effect of molecular weight of HPMC on the mechanism of drug release of naproxen sodium (NS) and naproxen (N) [145]. The study showed that matrices composed of various viscosity grades of HPMC are characterized by similar microviscosity values in spite of the difference in their molecular weight. $\mathrm{pH}$ measurements revealed that incorporation of $\mathrm{N}$ to HPMC matrix led to lower internal $\mathrm{pH}$ value inside the hydrated tablet compared with NS. This behavior led to lower solubility of $\mathrm{N}$ which dictates its surface erosion mechanism, compared with NS matrix that was characterized by higher internal $\mathrm{pH}$ value and higher drug solubility. These properties of HPMC/NS increased chain hydration and stability, and led to drug release by the diffusion mechanism.

Also there have been many studies demonstrating that the drug release profile from a hydrophilic matrix tablet is influenced by the viscosity of the gel layer formed due to its polymer hydration [146, 147]. However, little work has been done to study the influence of lot-to-lot apparent viscosity difference on in vitro dissolution. Also, not much has been done to compare the effect of using a single grade of HPMC versus a mixture of two different grades of HPMC on drug release [148]. The current apparent viscosity range specification for HPMC given by the manufacturer is $11,250-21,000 \mathrm{cps}$ [149] and two lots of this polymer may differ widely from each other in terms of apparent viscosity. Khanvilkar et al. studied the effects of a mixture of two different grades of HPMC and apparent viscosity on drug release profiles of extendedrelease matrix tablets. The study showed that lower and higher viscosity grades of HPMC can be mixed uniformly in definite proportions to get the desired apparent viscosity. Incorporating a low viscosity grade of HPMC in the formulation would lead to a significantly shorter $t_{\text {lag }}$ (lag time, the time taken by the matrix tablet edges to get hydrated and achieve a state of quasi equilibrium before erosion and the advance of solvent front through the matrix occur) however, it imposes minimal impact on the overall dissolution profile. Also the drug release from an HPMC matrix tablet prepared by dry blend and direct compression approach is independent of tablet hardness, is diffusion-controlled, and depends mostly on the viscosity of the gel layer formed [150]. Moreover by studying the distribution of HPMC within the tablet matrix Ye et al. found that manufacturing process has a significant impact in determining the dissolution characteristics of HPMC matrix tablets. When HPMC matrix tablets were prepared by wet-granulation approach, the tablet hardness, distribution of HPMC within the tablet (intergranular and intragranular), and the amount of water added in the wet granulation step all have a significant impact on dissolution. By incorporating partial amount of HPMC intergranularly in the dry-blend step, drug-release profiles could be made much less sensitive to the manufacturing process [151]. Liu et al. used alginate as the gelling agent in combination with HPMC which acted as a viscosity-enhancing agent in release of gatifloxacin. The rheological behaviors were not affected by the incorporation of gatifloxacin. Both in vitro release and in vivo pre-corneal retention studies indicated that the alginate/HPMC solution retained the drug better than the alginate or HPMC solutions alone. These results demonstrate that the alginate/HPMC mixture can be used as an in situ gelling vehicle to enhance ocular bioavailability and patient compliance [152].

Owing to the hydration and gel forming properties of HPMC, it can be used to prolong the release of active compound like yahom, yahom is a wellknown traditional remedy/medicine for treatment 
of nausea, vomiting, flatulent and unconscious in Thailand [153]. The yahom buccal tablet had antimicrobial activities that could be able to cure the oral microbial infection and aid the wound healing but the addition of polyvinyl pyrrolidone (PVP) combined with HPMC could promote the bioadhesive of yahom tablet [154]. Chantana et al. found that, the disintegration time of tablet was longer as the amount of polymer was increased or the higher amount of HPMC was enhanced, while the water sorption and erosion of tablet containing yahom: polymer mixture 50:50, which the polymer mixture containing PVP: HPMC 1:2 was lower than that of tablet containing these polymers at ratio of $1: 1$ and 2:1 respectively. This indicated that PVP had the higher water sorption and erosion, whereas HPMC could prolong the erosion of tablet. So, the tablet containing yahom $50 \%$, that had the polymer mixture of PVP: HPMC 1:2 was suitable to use as the buccal tablet since it had the low water sorption and erosion [155]. On the other hand, the combination of two or more excipients is frequently used in drug formulation to improve the tableting and release properties of the materials. In addition to the cellulose derivatives, crosslinked high amylose starch (CLA), has been successfully used as a controlled release excipient for the preparation of solid dosage forms [156]. Rahmouni et al. characterized the gel matrix properties of binary mixtures of CLA/ HPMC, and evaluated the effect of incorporated HPMC on the release kinetics of three model drugs of different solubilities such as pseudoephedrine sulfate (very soluble), sodium diclofenac (sparingly soluble), and prednisone (very slightly soluble) [157]. Swelling characteristics and erosion of granulated crosslinked high amylose starch (CLAgr)/ HPMC tablets were found to increase with HPMC concentration and incubation time. The equilibrium swelling and weight loss of CLAgr tablets were reached after $6 \mathrm{~h}$, whereas HPMC tablets continued to swell and erode even after $24 \mathrm{~h}$. HPMC is known to hydrate more rapidly than CLA, and forms a gel layer upon contact with aqueous medium. When the gel layer is sufficiently hydrated, the polymeric network begins to disintegrate and dissolve in the medium, resulting in matrix weight loss. Since CLA is a natural polysaccharide derivative, which does not much differ from HPMC, the same mechanism of hydration and erosion is expected for
CLA matrices. However, in this case, extensive swelling is restrained by the physical crosslinks, which limit tablet expansion and disintegration, the limited erosion observed with CLA tablets is probably related to the release of non-crosslinked amylose chains. The drug release experiments revealed that, in the absence of $\alpha$-amylase, both pseudoephedrine and sodium diclofenac were released more rapidly from CLAgr, CLAgr/HPMC and granulated CLA/HPMC tablets than HPMC matrices. Release of pseudoephedrine and sodium diclofenac was completed in approximately 12 and $22 \mathrm{~h}$, respectively, whereas only $30-35 \%$ prednisone was released after $24 \mathrm{~h}$ and all three drugs were probably released mainly by diffusion. The addition of $\alpha$-amylase to the dissolution medium increased substantially the release rate. It has been demonstrated that $\alpha$-amylase degrades CLA tablets into water-soluble degradation products, resulting in surface tablet erosion which enhances the release kinetics of poorly water soluble drugs [158, 159]. Introducing HPMC into CLA tablets at a concentration of 10\% may reduce the enzymatic hydrolysis by slowing down the diffusion of the enzyme in the substrate. However, this decrease in release rate was less significant for highly water soluble drugs, such as pseudoephedrine, which rapidly diffuses out of the matrix. So, swelling and erosion of the matrices increased with HPMC content and incubation time. In addition CLA formed stronger gels than HPMC or CLA/HPMC mixture and the presence of HPMC in CLA tablets at concentration $10 \%$ protected CLA against $\alpha$-amylase hydrolysis and reduced the release rate of poorly and moderately water-soluble drugs. The release of the highly water soluble model drug was rapid both in the presence or absence of HPMC, and occurred mainly by diffusion.

In another study the effect of the concentration of HPMC on naproxen release rate was studied, the dissolution results showed that an increased amount of HPMC resulted in reduced drug release. The inclusion of buffers to increase the dissolution and to decrease the gastric irritation of weak acid drugs, such as naproxen in the HPMC matrix tablets enhanced naproxen release. Naproxen is a weak acid, so it is more soluble in alkaline media. The inclusion of sodium bicarbonate and calcium carbonate in the HPMC matrix improved the 
naproxen dissolution; however, including sodium citrate did not produce any effect on naproxen dissolution [160].

The drug release for extended duration, particularly for highly water-soluble drugs, using a hydrophilic matrix system is restricted due to rapid diffusion of the dissolved drug through the hydrophilic gel network. For such drugs with high water solubility, hydrophobic polymers (waxes) are suitable as matrix forming agents for developing sustainedrelease dosage forms [161]. Hydrophobic polymers provide several advantages, ranging from good stability at varying $\mathrm{pH}$ values and moisture levels to well-established safe applications. Tramadol, which is a synthetic opioid of the aminocyclohexanol group, is freely soluble in water and hence judicious selection of release retarding excipients is necessary to achieve a constant in vivo input rate of the drug [162]. Sandip et al. studied the effect of concentration of hydrophilic (HPMC) and hydrophobic polymers (hydrogenated castor oil [HCO] and EC) on the release rate of tramadol [163]. The results showed that hydrophobic matrix tablets resulted in sustained in vitro drug release $(>20 \mathrm{~h})$ as compared with hydrophilic matrix tablets $(<14 \mathrm{~h})$. Figure 6 depicts the effect of HPMC on the tramadol release from hydrophilic matrices. Increasing the concentration of HPMC in the matrix did not alter the drug release profile significantly. Figure 7 shows the effect of EC on tramadol release

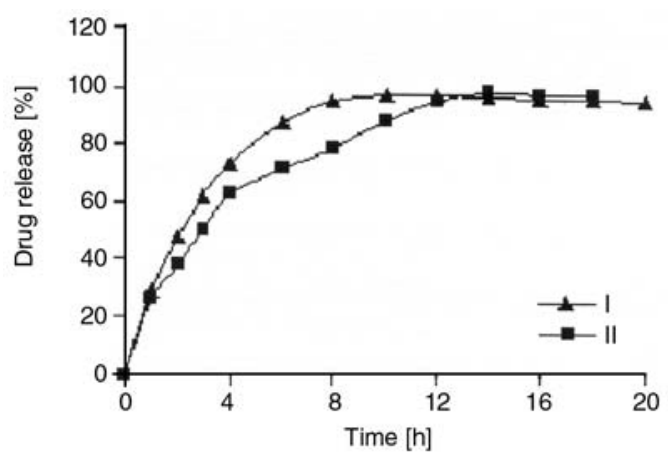

Figure 6. Effect of HPMC on tramadol release from hydrophilic matrix system prepared by wet granulation as per Table 5

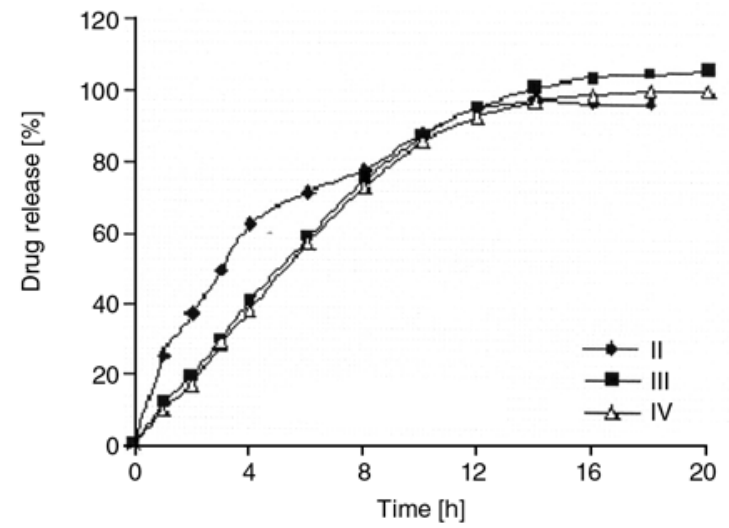

Figure 7. Effect of EC on tramadol release from hydrophilic matrix system prepared by wet granulation as per Table 5

from hydrophilic matrix system. The tablets formulations as in Table 5.

In another study the release kinetic profiles of naproxen (NP) from microcapsule compressed as well as matrix tablets using a combination of water insoluble materials (like bees wax (BW), cetyl alcohol (CA) and stearic acid (SA)) with hydrophilic polymers was investigated. The EC/HPMC combinations, contributing an increase in hydrophilic part of blend system rationally increased the release rate, kinetic constant and diffusion co-efficient thereby whereas HPMC/BW, HPMC/CA and HPMC/SA combinations, contributing an increase in hydrophobic part of the blend system caused a substantial reduction of release [164].

Also, Vueba et al. studied the influence of cellulose ether derivatives on ibuprofen release from matrix tablets formulations containing mixtures of polymers with both low and high viscosity grades MC or HPC, and HPMC, respectively were prepared by a direct compression method using 20, 25, and $30 \%$ of either MC or HPC [165]. The results obtained in this study illustrated that both low and high viscosity grade cellulose ether polymers can be mixed uniformly, in different proportions, in order to produce matrices with modulated drug release properties. On the other hand, the swelling experiments showed that the water uptake increases until the

Table 5. Tramadol $\mathrm{HCl} 200 \mathrm{mg}$ tablet formulations

\begin{tabular}{|l|r|r|r|r|r|r|r|r|}
\hline \multirow{2}{*}{\multicolumn{1}{c|}{ Excipients }} & \multicolumn{9}{c|}{ mg/Tablet } \\
\cline { 2 - 10 } & \multicolumn{1}{|c|}{ I } & II & III & IV & VI & VII & VIII & IX \\
\hline Hydrogenated castor oil & 0 & 0 & 0 & 0 & 200 & 200 & 200 & 200 \\
\hline Ethylcellulose & 0 & 0 & 10 & 20 & 0 & 5 & 10 & 20 \\
\hline HPMC K100 & 150 & 200 & 110 & 110 & 0 & 0 & 0 & 0 \\
\hline PVP K 90 & 10 & 10 & 10 & 10 & 0 & 0 & 0 & 0 \\
\hline
\end{tabular}


low viscosity polymer content reaches $25 \%$. At higher concentrations, the swelling behavior changes drastically, suggesting a gradual degradation of the matrices and the dissolution of ibuprofen from mixtures of MC/HPMC or HPC/HPMC matrices was found to be more effective when either the MC or HPC content was increased.

\subsection{Cellulose esters}

Cellulose acetate phthalate is a partial acetate ester of cellulose that has been reacted with phthalic anhydride. One carboxyl of the phthalic acid is esterified with the cellulose acetate. The finished product contains about $20 \%$ acetyl groups and about $35 \%$ phthalyl groups. In the acid form, it is soluble in organic solvents and insoluble in water. The salt formed is readily soluble in water. This combination of properties makes it useful in enteric coating of tablets because it is resistant to the acid condition of the stomach but soluble in the more alkaline environment of the intestinal tract [72].

\section{Conclusions}

Chemical modification of cellulose is performed to produce cellulose derivatives (cellulosics) which are in general strong, low cost, reproducible, recyclable and biocompatible, so they can be tailored for pharmaceutical applications.

Cellulose derivatives are often used to modify the release of drugs in tablet and capsule formulations and also as tablet binding, thickening and rheology control agents, for film formation, water retention, improving adhesive strength, for suspending and emulsifying.

MCC is used as diluent and disintegrating agent for release oral solid dosage. HEC and HPC are used in hydrophilic matrix systems, while EC can be used in hydrophobic matrix system. Also, liquid and semi-solid pharmaceutical dosage forms are important physicochemical systems for medical treatment which require rheological control and stabilizing excipients as essential additives, CMC can be used to adjust the viscosity of syrups.

\section{References}

[1] Alderman D. A. A.: Review of cellulose ethers in hydrophilic matrices for oral controlled-release dosage forms. International Journal of Pharmaceutical Technology and Product Manufacture, 5, 1-9 (1984).

[2] Heller J.: Use of polymers in controlled release of active agents. in 'Controlled Drug Delivery. Fundamentals and Applications' (eds.: Robinson J. R., Lee V. H. L.) Marcel Dekker, New York, 179-212 (1987).

[3] Longer M. A., Robinson J. R.: Sustained-release drug delivery systems. in 'Remington's Pharmaceutical Sciences' (Ed.: Remington J. P.) Mack Publishing, Easton, 1676-1693 (1990).

[4] Sandip B. T., Ali R.: Extended-release oral drug delivery technologies: monolithic matrix systems. Methods of Molecular Biology, 437, 217-243 (2008).

[5] Liu J., Lin S., Li L., Liu E.: Releases of theophylline from polymer blend hydrogels. International Journal of Pharmaceutics, 298, 117-125 (2005).

[6] Prokop A., Kozlov E., Carlesso G., Davidson J. M.: Hydrogel-based colloidal polymeric system for protein and drug delivery: physical and chemical characterization, permeability control and applications. Advances in Polymer Science, 160, 119-173 (2002).

[7] Zaikov G. E., Iordanskii A. P., Markin V. S.: Diffusion of electrolytes in polymers. VSP Science Press, Utrecht (1988).

[8] George S. C., Thomas S.: Transport phenomena through polymeric system. Progress in Polymer Science, 26, 985-1017 (2001).

[9] Lindholm T., Juslin M.: Controlled release tablets 3: Ethylcellulose coats containing surfactant and powdered matter. Pharmaceutical Industry, 44, 937-941 (1982).

[10] Rodriguez C. F., Bruneau N., Barra J., Alfonso D., Doelker E.: Hydrophilic cellulose derivatives as drug delivery carriers: Influence of substitution type on the properties of compressed matrix tablets. in 'Handbook of Pharmaceutical Controlled Release Technology' (ed.: Wise D. L.) Marcel Dekker, New York, 1-30 (2000).

[11] Lapidus H., Lord N. G.: Drug release from compressed hydrophilic matrices. Journal of Pharmaceutical Sciences, 57, 1292-1301 (1968).

[12] Bettini R., Colombo P., Massimo G., Catellani P. L., Vitali T.: Swelling and drug release in hydrogel matrices: Polymer viscosity and matrix porosity effects. The European Journal of Pharmaceutical Sciences, 2, 213-219 (1994).

[13] Campos-Aldrete M. E., Villafuerte-Robles L.: Influence of the viscosity grade and the particle size of HPMC on metronidazole release from matrix tablets. European Journal of Pharmaceutics and Biopharmaceutics, 43, 173-178 (1997). 
[14] Amaral H. M., Lobo S. J. M., Ferreira D. C.: Effect of hydroxypropyl methylcellulose and hydrogenated castor oil on naproxen release from sustained-release tablets. AAPS Pharmaceutical Science Technology, 2, 14-21 (2001).

[15] Ford J. L., Rubinstein M. H., Hogan J. E.: Formulation of sustained release promethazine hydrochloride tablets using hydroxypropyl methylcellulose matrices. International Journal of Pharmaceutics, 24, 327-338 (1985).

[16] Cheong L. W. S., Heng P. W. S., Wong L. F.: Relationship between polymer viscosity and drug release from a matrix system. Pharmaceutical Research, 9, 1510-1514 (1992).

[17] Tahara K., Yamamoto K., Nishihata T.: Overall mechanism behind matrix sustained release (SR) tablets prepared with hydroxypropyl methylcellulose. Journal of Controlled Release, 35, 59-66 (1995).

[18] Krögel I., Bodmeier R.: Development of a multifunctional matrix drug delivery system surrounded by an impermeable cylinder. Journal of Controlled Release, 61, 43-50 (1999).

[19] Shah N., Zhang G., Apelian V., Zeng F., Infield M. H., Malick A. W.: Prediction of drug release from hydroxypropyl methylcellulose (HPMC) matrices: Effect of polymer concentration. Pharmaceutical Research, 10, 1693-1695 (1993).

[20] Xu G., Sunada H.: Influence of formulation change on drug release kinetics from hydroxypropyl methylcellulose matrix tablets. Chemical and Pharmaceutical Bulletin, 43, 483-487 (1995).

[21] Velasco M. V., Ford J. L., Rowe P., Rajabi-Siahboomi A. R.: Influence of drug: Hydroxypropyl methylcellulose ratio, drug and polymer particle size and compression force on the release of diclofenac sodium from HPMC tablets. Journal of Controlled Release, 57, 75-85 (1999).

[22] Mitchell K., Ford J. L., Armstrong D. J., Elliot P. N. C., Hogan J. E., Rostron C.: The influence of substitution type on the performance of methyl cellulose and hydroxypropyl methylcellulose in gels and matrices. European Journal of Pharmaceutics and Biopharmaceutics, 100, 143-154 (1993).

[23] Sheskey P. J., Williams D. M.: Comparison of lowshear and high-shear wet granulation techniques and the influence of percent water addition in the preparation of a controlled-release matrix tablet containing HPMC and a highdose, highly water-soluble drug. Pharmaceutical Technology, 20, 81-92 (1996).

[24] Bettini R., Colombo P., Massimo G., Catellani P. L., Vitali T.: Swelling and drug release in hydrogel matrices: Polymer viscosity and matrix porosity effects. The European Journal of Pharmaceutical Sciences, 2, 213-219 (1994).

[25] Ford J. L., Rubinstein M. H., Hogan J. E.: Formulation of sustained release promethazine hydrochloride tablets using hydroxypropyl methylcellulose matrices. International Journal of Pharmaceutics, 24, 327-338 (1985).
[26] Selkirk A. B., Ganderton D.: The influence of wet and dry granulation methods on the pore structure of lactose tablets. Journal of Pharmaceutical and Pharmacology, 22, 86S-94S (1970).

[27] Huber H. E., Christenson G. L.: Utilisation of hydrophilic gums for the control of drug substance release from tablet formulations II. Influence of tablet hardness and density on dissolution behavior. Journal of Pharmaceutical Sciences, 57, 164-166 (1968).

[28] Genc L., Bilac H., Güler E.: Studies on controlled release dimenhydrinate from matrix tablet formulations. Pharmaceutical Acta Helvetiae, 74, 43-49 (1999).

[29] Chalmers A. A., Elworthy P. H.: Oxytetracycline tablet formulations: The influence of excipients and the method of granulation. Journal of Pharmaceutical and Pharmacology, 28, 234-238 (1976).

[30] Chowhan Z. T., Yang I-C.: Effect of intergranular versus intragranular corn starch on tablet friability and in vitro dissolution. Journal of Pharmaceutical Sciences, 72, 983-988 (1983).

[31] Khattab I., Menon A., Sakr A.: Effect of mode of incorporation of disintegrants on the characteristics of fluid-bed wet-granulated tablets. Journal of Pharmaceutical and Pharmacology, 45, 687-691 (1993).

[32] Li J. Z., Rekhi G. S., Augsburger L. L., Shangraw R. F.: The role of intra- and extragranular microcrystalline cellulose in tablet dissolution. Pharmaceutical Development and Technology, 1, 343-355 (1996).

[33] Zhang Y. E., Tchao R., Schwartz J. B.: Effect of processing methods and heat treatment on the formation of wax matrix tablets for sustained drug release. Pharmaceutical Development and Technology, 6, 131144 (2001).

[34] Hinterstoisser B., Salmen L.: Application of dynamic 2D FTIR to cellulose. Vibrational Spectroscopy, 22, 111-118 (2000).

[35] Bochek A. M.: Effect of hydrogen bonding on cellulose solubility in aqueous and nonaqueous solvents. Russian Journal of Applied Chemistry, 76, 17111719 (2003).

[36] Myasoedova V. V.: Physical chemistry of non-aqueous solutions of cellulose and its derivatives. John Wiley and Sons, Chirchester (2000).

[37] Gross R. A., Scholz C.: Biopolymers from polysaccharides and agroproteins. American Chemical Society, Washington (2000).

[38] Akira I.: Chemical modification of cellulose. in 'Wood and Cellulosic Chemistry' (eds.: Hon D. N-S., Shiraishi N.) Marcel Dekker, New York, 599-626 (2001).

[39] Conner A. H.: Size exclusion chromatography of cellulose and cellulose derivatives. in 'Handbook of Size Exclusion Chromatography' (ed.: Wu C-S.) Marcel Dekker, New York, 331-352 (1995).

[40] Sjostrom E.: Wood chemistry, fundamentals and applications. Academic Press, New York (1993). 
[41] Kuga S., Brown R. M. Jr.: Silver labeling of the reducing ends of bacterial cellulose. Carbohydrate Research, 180, 345-350 (1988).

[42] Saxena I. M., Bown R. M.: Cellulose biosynthesis: Current views and evolving concepts. Annals of Botany, 96, 9-21 (2005).

[43] Kolpak F. J., Blackwell J.: Determination of the structure of cellulose II. Macromolecules, 9, 273-278 (1976).

[44] Langan P., Nishiyama Y., Chanzy H.: A revised structure and hydrogen-bonding system in cellulose II. From a neutron fiber diffraction analysis. Journal of American Chemical Society, 121, 9940-9946 (1999).

[45] Wada M., Heux L., Isogai A., Nishiyama Y., Chanzy H., Sugiyama J.: Improved structural data of cellulose III $_{\text {I }}$ prepared in supercritical ammonia. Macromolecules, 34, 1237-1243 (2001).

[46] Sarko A., Southwick J., Hayashi J.: Packing analysis of carbohydrates and polysaccharides. 7. crystal structure of cellulose $\mathrm{III}_{\mathrm{I}}$ and its relationship to other cellulose polymorphs. Macromolecules, 9, 857-863 (1976).

[47] Chanzy H., Vincendon M., Henrissat B., Tanner S. F., Belton P. S.: Solid state ${ }^{13} \mathrm{C}-\mathrm{NMR}$ and electron microscopy study on the reversible transformation cellulose I-cellulose $\mathrm{III}_{\mathrm{I}}$ in Valonia. Carbohydrate Research, 160, 1-11 (1987).

[48] Buleon A., Chanzy H.: Single crystals of cellulose $\mathrm{IV}_{\mathrm{II}}$. Preparation and properties. Journal of Polymer Science: Polymer Physics Edition, 18, 1209-1217 (1980).

[49] Klemm D., Heublein B., Fink H-P. Bonn A.: Cellulose: Fascinating biopolymer and sustainable raw material. Angewandte Chemie, International Edition, 44, 3358-3393 (2005).

[50] Nabar G. M., Padmanabhan C. V.: Studies in oxycellulose. Proceedings of the Indian Academy of Sciences: A, 31, 371-80 (1950).

[51] Da Silva Perez D., Montanari S., Vignon M. R.: TEMPO-mediated oxidation of cellulose III. Biomacromolecules, 4, 1525-1425 (2003).

[52] Chang P. S., Robyt J. F.: Oxidation of primary alcohol groups of naturally occurring polysaccharides with 2,2,6,6-tetramethyl-1-piperidine oxoammonium ion. Journal of Carbohydrate Chemistry, 15, 819-830 (1996).

[53] Manderson K., Pinart M., Tuohy K. M., Grace W. E., Hotchkiss A. T., Widmer W., Yadhav M. P., Gibson G. R., Rastall R. A.: In vitro determination of prebiotic properties of oligosaccharides derived from an orange juice manufacturing by-product stream. Applied and Environmental Microbiology, 71, 83838389 (2005).

[54] Kim U-J., Kuga S., Wada M., Okano T., Kondo T.: Periodate oxidation of crystalline cellulose. Biomacromolecules, 1, 488-492 (2000).
[55] Bogaard J., Morris H. R., Whitmore P. M.: A method for the aqueous deacidification of oxidized paper. Journal of the American Institute for Conservation, 44, 63-74 (2005).

[56] Lichtenthale F. W.: Ullmann's encyclopedia of industrial chemistry. 6th edition: Carbohydrates. WileyVCH, Weinheim (2002).

[57] Sun Y., Lin L., Deng H., Li J., He B., Sun R., Ouyang P.: Structural changes of bamboo cellulose in formic acid. Bioresources, 3, 297-315 (2008).

[58] Reier C. E., Shangraw R. F.: Microcrystalline cellulose in tableting. Journal of Pharmaceutical Sciences, 55, 510-515 (1966).

[59] Durand H. W., Fleck E. J., Raynor G. E.: Microcrystalline cellulose compositions Co-dried with hydrocelluloses. US patent 3537 058, USA (1970).

[60] Battista O. A., Smith P. A.: Microcrystalline cellulose. Industrial and Engineering Chemistry, 54, 20-29 (1962).

[61] Baruah P. P., Bhattacharya G. C., Chaliha B. P.: Microcrystalline cellulose from cotton. Indian Pulp and Paper, 971-976 (2000).

[62] Bhimte N. A., Tayade P. T.: Evaluation of microcrystalline cellulose prepared from sisal fibers as a tablet excipient: A technical note. AAPS Pharmaceutical Science and Technology, 8, 1-6 (2007).

[63] Anand S. M., Chawla J. S.: Microcrystalline cellulose from hosiery waste. Research and Industry, 26, 227 235 (1981).

[64] Nagavi B. G, Mithal B. M., Chawla J. S.: Microcrystalline cellulose from corncobs. Research Industry, 28, 277-280 (1989).

[65] Jain A. K., Dixit V. K., Varma K. C.: Preparation of microcrystalline cellulose from cereal straw and its evaluation as a tablet excipient. Industrial Journal of Pharmaceutical Science, 3, 83-85 (1983).

[66] El-Sakhawy M., Hassan M. L.: Physical and mechanical properties of microcrystalline cellulose prepared from agricultural residues. Carbohydrate Polymers, 67, 1-10 (2007).

[67] Hakansson H., Ahlgren P.: Acid hydrolysis of some industrial pulps: Effect of hydrolysis. Cellulose, 12, 177-183 (2005).

[68] Kaputskii F. N., Gert E. V., Torgashov V. I., Zubets O. V.: Hydrogels for medical applications fabricated by oxidative-hydrolytic modification of cellulose. Fiber Chemistry, 37, 485-489 (2005).

[69] Kirk R., Othmer D.: Encyclopedia of chemical technology. John Wiley, New York (1968).

[70] Cohen S. G., Haas H. C., Farney L., Valle C. Jr.: Preparation and properties of some ether and ester derivatives of hydroxyethylcellulose. Industrial and Engineering Chemistry, 45, 200-203 (1953).

[71] Wadworth L. C., Daponte D.: Cellulose esters. in 'Cellulose Chemistry and its Applications' (eds.: Nevell T. P., Zeronian S. H.) Ellis Horwood, Chichester, 349-362 (1985). 
[72] Delgado J. N., William A.: Wilson and Gisvold's textbook of organic medicinal and pharmaceutical chemistry. Lippincott-Raven Publishers, Wickford (1998).

[73] Banker G. S., Kumar V.: Microfibrillated oxycellulose. US patent 5405953, USA (1995).

[74] Kibbe A. H.: Handbook of pharmaceutical excipients: Cellulose, silicified microcrystalline. American Public Health Association, Washington (2000).

[75] Luukkonen P., Schaefer T., Hellen J., Juppo A. M., Yliruusi J.: Rheological characterization of microcrystalline cellulose and silicified microcrystalline cellulose wet masses using a mixer torque rheometer. International Journal of Pharmaceutics, 188, 181-192 (1999).

[76] Edge S., Steele F., Chen A., Tobyn M., Staniforth J. N.: The mechanical properties of compacts of microcrystalline cellulose and silicified microcrystalline cellulose. International Journal of Pharmaceutics, 200, 67-72 (2000).

[77] Van Veen B., Bolhuis G. K., Wu Y. S., Zuurman K., Frijlink H. W.: Compaction mechanism and tablet strength of unlubricated and lubricated (silicified) microcrystalline cellulose. European Journal of Pharmaceutics and Biopharmaceutics, 59, 133-138 (2005).

[78] Sherwood B. E., Becker J. W.: A new class of high functionality excipients: Silicified microcrystalline cellulose. Pharmaceutical Technology, 22, 78-88 (1998).

[79] Guo M., Augsburger L. L.: Potential application of silicified microcrystalline cellulose in direct-fill formulations for automatic capsule-filling machines. Pharmaceutical Development and Technology, 8, 4759 (2003).

[80] Zografi G., Kontny M. J., Yang A. Y. S., Brenner G. S.: Surface area and water vapor sorption of microcrystalline cellulose. International Journal of Pharmaceutics, 18, 99-116 (1984).

[81] Hwang R-C., Peck G. R.: A systematic evaluation of the compression and tablets characteristics of various types of microcrystalline cellulose. Pharmaceutical Technology, 24, 112-132 (2001).

[82] Muzíková J., Nováková P.: A study of the properties of compacts from silicified microcrystalline celluloses. Drug Development and Industrial Pharmacy, 33, 775-781 (2007).

[83] Siepmann J., Kranz H., Bodmeier R., Peppas N. A.: HPMC-matrices for controlled drug delivery: a new model combining diffusion, swelling, and dissolution mechanisms and predicting the release kinetics. Pharmaceutical Research, 16, 1748-1756 (1999).

[84] Colombo P., Bettini R., Peppas N. A.: Observation of swelling process and diffusion front position during swelling in hydroxypropylmethyl cellulose (HPMC) matrices containing a soluble drug. Journal of Controlled Release, 61, 83-91 (1999).
[85] Lowman A. M., Peppas N. A.: Hydrogels. in 'Encyclopedia of Controlled Drug Delivery' (ed.: Mathiowitz E.) Wiley, New York, 397-417 (2000).

[86] Le Neel T., Morlet-Renaud C., Lipart C., Gouyette A., Truchaud A., Merle C.: Image analysis as a new technique for the study of water uptake in tablets. STP Pharma Sciences, 7, 117-122 (1997).

[87] Baumgartner S., Šmid-Korbar J., Vreèer F., Kristl J.: Physical and technological parameters influencing floating properties of matrix tablets based on cellulose ethers. STP Pharmaceutical Sciences, 8, 182-187 (1998)

[88] Arion H.: Carboxymethyl cellulose hydrogel-filled breast implants. Our experience in 15 years (in French). Annales de Chirurgie Plastique et Esthétique, 46, 55-59 (2001).

[89] Hercules Incorporated, Aqualon Division: http://www.aqualon.com (16.07.2008).

[90] Sannino A., Madaghiele M., Conversano F., Mele G., Maffezzoli A., Netti P. A., Ambrosio L., Nicolais L.: Cellulose derivative-hyaluronic acid-based microporous hydrogels crosslinked through divinyl sulfone (DVS) to modulate equilibrium sorption capacity and network stability. Biomacromolecules, 5, 92-673 (2004).

[91] Valeriani M., Mezzana P., Madonna S., Terracina F.: Carboxy-methyl-cellulose hydrogel mammary implants: Our experience. Acta Chirurgiae Plasticae, 44, 71-76 (2002).

[92] Domínguez A., Valdivia A., Hernández J., Villalonga R.: Biocompatibilid in vitro de Superóxido dismutasa interactuando con polímero e hidrogeles de carboximetilcelulosa ensayado con fibroblastos humanos. Revista de Biotecnología Aplicada, 21, 218-2381 (2004).

[93] Domínguez A.: Modifying superoxide dismutase for improved biopharmaceutical properties. Biotecnología Aplicada, 23, 17-21 (2006).

[94] Klestov A. C., Webb J., Latt D., Schiller G., McNamara K., Young D. Y., Hobbes J., Fetherston J.: Treatment of xerostomia: A double-blind trial in 108 patients with Sjögren's syndrome. Oral Surgery Oral Medicine and Oral Pathology, 51, 594-599 (1981).

[95] Olsson H., Axell T.: Objective and subjective efficacy of saliva substitutes containing mucin and carboxymethyl cellulose. Scandinavian Journal of Dental Research, 99, 316-319 (1991).

[96] Rokhade A. P., Agnihotri S. A., Patil S. A., Mallikarjuna N. N., Kulkarni P. V., Aminabhavi T. M.: Semiinterpenetrating polymer network microspheres of gelatin and sodium carboxymethyl cellulose for controlled release of ketorolac tromethamine. Carbohydrate Polymers, 65, 243-252 (2006).

[97] Flower R. J., Moncada S., Vane J. R.: Indomethacin. in 'Goodman and Gilman's the Pharmacological Basis of Therapeutics' (eds.: Hardman J. G., Limbird L. E.) Macmillan Publishing, New York, 695-697 (1990) 
[98] Waree T., Garnpimol C. R.: Development of indomethacin sustained release microcapsules using chitosan-carboxymethyl cellulose complex coacervation. Songklanakarin Journal of Science Technology, 25, 245-254 (2003).

[99] Ritthidej G. C., Tiyaboonchai W.: Formulation and drug entrapment of microcapsules prepared from chitosan-carboxymethylcellulose complex coacervation. Thai Journal of Pharmaceutical Sciences, 21, 137144 (1997).

[100]Hou W. M., Miyasaki S., Takada M., Komai T.: Sustained release of indomethacin from chitosan granules. Chemical and Pharmaceutical Bulletin, 33, 3986-3992 (1985).

[101] Thanoo B. C., Sunny M. C., Jayakrishnan A.: Crosslinked chitosan microspheres: Preparation and evaluation as a matrix for the controlled release of pharmaceuticals. Journal of Pharmacy and Pharmacology, 44, 283-286 (1992).

[102]Polk A., Amsden B., De Yao K., Peng T., Goosen M. F.: Controlled release of albumin from chitosan-alginate microcapsules. Journal of Pharmaceutical Sciences, 83, 178-195 (1994).

[103]Remunan-Lopez C., Bodmeier R.: Effect of formulation and processing variables on the formation of chitosan-gelatin coacervates. International Journal of Pharmaceutics, 135, 63-72 (1996).

[104] Kunal P., Banthia A. K., Majumdar D. K.: Esterification of carboxymethyl cellulose with acrylic acid for targeted drug delivery system. Trends in Biomaterials and Artificial Organs, 19, 12-14 (2005).

[105]Kunal P., Banthia A. K., Majumdar D. K.: Development of carboxymethyl cellulose acrylate for various biomedical applications. Biomedical Materials, 1, 85-91 (2006).

[106]Wilkes G. M.: Consumers guide to cancer drugs (American Cancer Society). Jones and Bartlett Publishers, Sudbury (2004).

[107]Keiji S., Noboru O.: Studies on absorption of eutectic mixture. I. A comparison of the behavior of eutectic mixture of sulfathiazole and that of ordinary sulfathiazole in man. Chemical and Pharmaceutical Bulletin, 9, 866-872 (1961).

[108]Chiou W. L., Riegelman S.: Oral absorption of griseofulvin in dogs. Increased absorption via solid dispersion in polyethylene glycol 6000. Journal of Pharmaceutical Sciences, 59, 937-942 (1970).

[109]Sugimoto I., Kuchiki A., Nakagawa H., Tohgo A., Kondo S., Iwane I., Takahashi K.: Dissolution and absorption of nifedipine from nifedipine-polyvinylpyrrolidone coprecipitate. Drug Development and Industrial Pharmacy, 6, 137-160 (1980).

[110]Takeuchi H., Handa T., Kawashima Y.: Spherical solid dispersion containing amorphous tolbutamide embedded in enteric coating polymers or colloidal silica prepared by spray-drying technique. Chemical and Pharmaceutical Bulletin, 35, 3800-3806 (1987).
[111]Suzuki H., Sunada H.: Influence of water-soluble polymers on the dissolution of nifedipine solid dispersions with combined carriers. Chemical and Pharmaceutical Bulletin, 46, 482-487 (1998).

[112]Ozeki T., Yuasa H., Okada H.: Controlled release of drug via methylcellulose-carboxyvinyl polymer interpolymer complex solid dispersion. AAPS Pharmaceutical Science and Technology, 6, 231-236 (2005).

[113]Mura P., Faucci M. T., Manderioli A., Bramanti G., Parrini P.: Thermal behavior and dissolution properties of naproxen from binary and ternary solid dispersion. Drug Development and Industrial Pharmacy, 25, 257-264 (1999).

[114]Friedman M., Golomb G.: New sustained release dosage form of chlorhexidine for dental use. Journal of Periodontal Research, 17, 323-328 (1982).

[115] Soskolne W. A., Golomb G., Friedman M., Sela M. N.: New sustained release dosage form of chlorhexidine for dental use. Journal of Periodontal Research, 18, 330-336 (1983).

[116] Yuasa H., Ozeki T., Kanaya Y., Oishi K., Oyake T.: Application of the solid dispersion method to the controlled release of medicine. I. Controlled release of water soluble medicine by using solid dispersion. Chemical and Pharmaceutical Bulletin, 39, 465-467 (1991).

[117] Yuasa H., Ozeki T., Kanaya Y., Oishi K.: Application of the solid dispersion method to the controlled release of medicine. II. Sustained release tablet using solid dispersion granule and the medicine release mechanism. Chemical and Pharmaceutical Bulletin, 40, 1592-1596 (1992).

[118]Ozeki T., Yuasa H., Kanaya Y., Oishi K.: Application of the solid dispersion method to the controlled release of medicine. V. Suppression mechanism of the medicine release rate in the three-component solid dispersion system. Chemical and Pharmaceutical Bulletin, 42, 337-343 (1994).

[119]Ozeki T., Yuasa H., Kanaya Y., Oishi K.: Application of the solid dispersion method to the controlled release of medicine. VII. Release mechanism of a highly water-soluble medicine from solid dispersion with different molecular weight of polymer. Chemical and Pharmaceutical Bulletin, 43, 660-665 (1995).

[120]Ozeki T., Yuasa H., Kanaya Y., Oishi K.: Application of the solid dispersion method to the controlled release of medicine. VIII. Medicine release and viscosity of the hydrogel of a water-soluble polymer in athree-component solid dispersion system. Chemical and Pharmaceutical Bulletin, 43, 1574-1579 (1995).

[121] Yuasa H., Takahashi H., Ozeki T., Kanaya Y., Ueno M.: Application of the solid dispersion method to the controlled release of medicine. III. Control of the release rate of slightly water soluble medicine from solid dispersion granules. Chemical and Pharmaceutical Bulletin, 41, 397-399 (1993). 
[122] Yuasa H., Ozeki T., Takahashi H., Kanaya Y., Ueno M.: Application of the solid dispersion method to the controlled release of medicine. VI. Release mechanism of slightly water soluble medicine and interaction between flurbiprofen and hydroxypropyl cellulose in solid dispersion. Chemical and Pharmaceutical Bulletin, 42, 354-358 (1994).

[123] Ozeki T., Yuasa H., Kanaya Y.: Application of the solid dispersion method to the controlled release of medicine. IX. Difference in the release of flurbiprofen from solid dispersions with poly(ethylene oxide) and hydroxypropylcellulose and interaction between medicine and polymers. International Journal of Pharmaceutics, 115, 209-217 (1997).

[124]Nagai T., Machida Y.: Advances in drug delivery: Mucosal adhesive dosage forms. Pharmaceutical International, 6, 196-200 (1985).

[125]Satoh K., Takayama K., Machida Y., Suzuki Y., Nakagaki M., Nagai T.: Factors affecting the bioadhesive property of tablets consisting of hydroxypropyl cellulose and carboxyvinyl polymer. Chemical and Pharmaceutical Bulletin, 37, 1366-1368 (1989).

[126]Han R-Y., Fang J-Y., Sung K. C., Hu O. Y. P.: Mucoadhesive buccal disks for novel nalbuphine prodrug controlled delivery: Effect of formulation variables on drug release and mucoadhesive performance. International Journal of Pharmaceutics, 177, 201-209 (1999).

[127]Chen W-G., Hwang G. C-C.: Adhesive and in vitro release characteristics of propranolol bioadhesive disc system. International Journal of Pharmaceutics, 82, 61-66 (1992).

[128]Park C. R., Munday D. L.: Development and evaluation of a biphasic buccal adhesive tablet for nicotine replacement therapy. International Journal of Pharmaceutics, 237, 215-226 (2002).

[129]Lo Muzio L., Della Valle A., Mignogna M. D., Pannone G., Bucci P., Bucci E., Sciubba J.: The treatment of oral aphthous ulceration or erosive lichen planus with topical clobetasol propionate in three preparations: A clinical and pilot study on 54 patients. Journal of Oral Pathology and Medicine, 30, 611-617 (2001).

[130] Senel S., Hincal A. A.: Drug permeation enhancement via buccal route: Possibilities and limitations. Journal of Controlled Release, 72, 133-144 (2001).

[131]Okamoto H., Nakamori T., Arakawa Y., Iida K., Danjo K.: Development of polymer film dosage forms of lidocaine for buccal administration. II. Comparison of preparation methods. Journal of Pharmaceutical Sciences, 91, 2424-2432 (2002).

[132] Mizrahi B., Golenser J., Wolnerman J. S., Domb A. J.: Adhesive tablet effective for treating canker sores in humans. Journal of Pharmaceutical Sciences, 93, 2927-2935 (2004).
[133]Gurruchaga M., Goñi I., Valero M., Guzmán G. M.: Graft polymerisation of acrylic monomers onto starch fractions. I. Effect of reaction time on grafting MMA onto amylopectin. Journal of Polymer Science, Part A: Polymer Chemistry, 21, 2573-2580 (1983).

[134]Gander B., Gurny R., Doelker E., Peppas N. A.: Crosslinked poly(alkylene oxides) for the preparation of controlled release micromatrices. Journal of Controlled Release, 5, 271-283 (1988).

[135]Gon M. C., Ferrero R. M., Jimenez C., Gurruchaga M.: Synthesis of hydroxypropyl methacrylate/ polysaccharide graft copolymers as matrices for controlled release tablets. Drug Development and Industrial Pharmacy, 28, 1101-1115 (2002).

[136]Tahara K., Yamamoto K., Nishihata T.: Overall mechanism behind matrix sustained release (SR) tablets prepared with hydroxypropylmethyl cellulose. Journal of Controlled Release, 35, 59-66 (1995).

[137]Skoug J. W., Mikelsons M. V., Vigneron C. N., Stemm N. L.: Qualitative evaluation of the mechanism of release of matrix sustained release dosage forms by measurement of polymer release. Journal of Controlled Release, 27, 227-245 (1993).

[138]Ford J. L., Rubinstein M. H., McCaul F., Hogan J. E., Edgar P. J.: Importance of drug type, tablet shape and added diluents on drug release kinetics from hydroxypropylmethyl cellulose matrix tablets. International Journal of Pharmaceutics, 40, 223-234 (1987).

[139]Ranga Rao K V., Padmalatha D., Buri P.: Influence of molecular size and water solubility of the solute on its release from swelling and erosion controlled polymeric matrices. Journal of Controlled Release, 12, 133-141 (1990).

[140]Harland R. S., Gazzaniga A., Sangalli M. E., Colombo P., Peppas N. A.: Drug/polymer matrix swelling and dissolution. Pharmaceutical Research, 5, 488-494 (1988).

[141]Lee P. I.: Diffusional release of a solute from a polymeric matrix-approximate analytical solution. Journal of Membrane Science, 7, 255-275 (1980).

[142]Lee P. I., Peppas N. A.: Prediction of polymer dissolution in swellable controlled-release systems. Journal of Controlled Release, 6, 207-215 (1987).

[143]Reynolds T. D., Gehrke S. H., Hussain A. S., Shenouda S. L.: Polymer erosion and drug release characterization of hydroxypropylmethyl cellulose matrices. Journal of Pharmaceutical Sciences, 87, 1115-1123 (1998).

[144]Reynolds T. D., Mitchell S. A., Balwinski K. M.: Investigation of the effect of tablet surface area/volume on drug release from hydroxypropylmethylcellulose controlled-release matrix tablets. Drug Development and Industrial Pharmacy, 28, 457-466 (2002).

[145] Katzhendler I., Mader K., Friedman M.: Structure and hydration properties of hydroxypropyl methylcellulose matrices containing naproxen and naproxen sodium. International Journal of Pharmaceutics, 200, 161-179 (2000). 
[146]Lee P. I.: Kinetics of drug release from hydrogel matrices. Journal of Controlled Release, 2, 277-288 (1985).

[147]Colombo P.: Swelling-controlled release in hydrogel matrices for oral route. Advanced Drug Delivery Reviews, 11, 37-57 (1993).

[148] Vazquez M-J., Casalderrey M., Duro R., GómezAmoza J-L., Martinez-Pacheco R., Souto C., Concheiro A.: Atenolol release from hydrophilic matrix tablets with hydroxypropylmethylcellulose (HPMC) mixtures as gelling agent: Effects of the viscosity of the HPMC mixture. The European Journal of Pharmaceutical Sciences, 4, 39-48 (1996).

[149]Alvarez-Lorenzo C., Duro R., Gomez-Amoza J. L., Martinez-Pacheco R., Souto C., Concheiro A.: Influence of polymer structure on the rheological behavior of hydroxypropylmethylcellulose-sodium carboxymethylcellulose dispersions. Colloid and Polymer Science, 279, 1045-1057 (2001).

[150]Khanvilkar K. H., Ye H., Moore A. D.: Influence of hydroxypropyl methylcellulose mixture, apparent viscosity, and tablet hardness on drug release using a $2^{3}$ full factorial design. Drug Development and Industrial Pharmacy, 28, 601-608 (2002).

[151]Ye H., Khanvilkar K. H., Moore A. D., Hilliard-Lott M.: Effects of manufacturing process variables on in vitro dissolution characteristics of extended-release tablets formulated with hydroxypropylmethyl cellulose. Drug Development and Industrial Pharmacy, 29, 79-88 (2003).

[152]Liu Z., Li J., Nie S., Liu H., Ding P., Pan W.: Study of an alginate/HPMC-based in situ gelling ophthalmic delivery system for gatifloxacin. International Journal of Pharmaceutics, 315, 12-17 (2006).

[153] Suvitayavat W., Tunglert S., Thirawarapan S. S., Bunyapraphatsara N.: Effects of Ya-hom on blood pressure in rats. Journal of Ethnopharmacology, 97, 503-508 (2005).

[154]Phaechamu T., Vesapun C., Kraisit P.: Ya Hom in dosage form of buccal tablet. in 'Proceedings of the $10^{\text {th }}$ World Congress on Clinical Nutrition. Phuket, Thailand' 193-198 (2004).

[155]Chantana V., Juree C., Thawatchaj P.: Effect of hydroxypropylmethyl cellulose and polyvinyl pyrrolidone on physical properties of Yahom buccal tablets and the antimicrobial activity of Yahom. in 'The $4^{\text {th }}$ Thailand Materials Science Technology Conference. Khong Wan, Thailand' PP01/1-PP01/3 (2006).
[156]Lenaerts V., Dumoulin Y., Mateescu M. A.: Controlled release of theophylline from cross-linked amylose tablets. Journal of Controlled Release, 15, 39-46 (1991).

[157]Rahmouni M., Lenaerts V., Massuelle D., Doelker E., Johnson M., Leroux J-C.: Characterization of binary mixtures consisting of cross-linked high amylase starch and hydroxypropylmethyl cellulose used in the preparation of controlled release tablets. Pharmaceutical Development and Technology, 8, 335-348 (2003).

[158]Rahmouni M., Chouinard F., Nekka F., Lenaerts V., Leroux J-C.: Enzymatic degradation of crosslinked high amylose starch tablets and its effect on in vitro release of sodium diclofenac. European Journal of Pharmaceutics and Biopharmaceutics, 51, 191-198 (2001).

[159]Chowhan Z. T.: Role of binder in moisture-induced hardness increase in compressed tablets and its effect on in vitro disintegration and dissolution. Journal of Pharmaceutical Sciences, 69, 1-4 (1980).

[160]Amaral M. H., Sousa Lobo J. M., Ferreira D. C.: Effect of hydroxypropylmethyl cellulose and hydrogenated castor oil on naproxen release from sustained-release tablets. APS Pharmaceutical Science and Technology, 2, 1-8 (2001).

[161]Liu J., Zhang F., McGinity J. W.: Properties of lipophilic matrix tablets containing phenylpropanolamine hydrochloride prepared by hot-melt extrusion. European Journal of Pharmaceutics and Biopharmaceutics, 52, 181-190 (2001).

[162] Salsa T., Veiga F., Pina M. E.: Oral controlled-release dosage forms. I. Cellulose ether polymers in hydrophilic matrices. Drug Development and Industrial Pharmacy, 23, 929-938 (1997).

[163] Sandip B., Tiwari T., Krishna M., Raveendra Pai M., Pavak R. M., Pasula B. C.: Controlled release formulation of tramadol hydrochloride using hydrophilic and hydrophobic matrix system. AAPS Pharmaceutical Science and Technology, 4, 1-6 (2003).

[164]Molla M. A. K., Shaheen S. M., Rashid M., Hossain A. K. M. M.: Rate controlled release of naproxen from HPMC Based sustained release dosage form, I. Microcapsule compressed tablet and matrices. Dhaka University Journal of Pharmaceutical Sciences, 4, (2005).

[165]Vueba M. L., Batista de Carvalho L. A. E., Veiga F., Sousa J. J., Pina M. E.: Influence of cellulose ether mixtures on Ibuprofen release: MC25, HPC and HPMC K100M. Pharmaceutical Development and Technology, 11, 213-228 (2006). 